\title{
Chlorophyll fluorescence for prediction of yellow lupin (Lupinus luteus L.) and pea (Pisum sativum L.) susceptibility to drought
}

\author{
K. JUZOŃ, I. CZYCZYŁO-MYSZA, A. OSTROWSKA, I. MARCIŃSKA, and E. SKRZYPEK ${ }^{+}$ \\ The Franciszek Górski Institute of Plant Physiology, Polish Academy of Sciences, Niezapominajek 21, \\ 30-239 Kraków, Poland
}

\begin{abstract}
Drought has become an essential environmental factor limiting plant productivity. In order to detect differences in chlorophyll (Chl) $a$ fluorescence, Chl concentration (in SPAD units), and yield parameters of yellow lupin ('Morocco 4' and 'Taper') and pea ('Wenus' and 'SZD165'), drought stress was initiated by withholding water for $14 \mathrm{~d}$ ( $25 \%$ of field water capacity). A significant decrease of leaf relative water content was found in tested cultivars. SPAD values did not show significant changes in all cultivars. The maximum photochemical efficiency and area over the Chl $a$ fluorescence induction curve decreased in both species under drought. Performance index in lupin did not change significantly under drought while it declined in pea. Among the tested cultivars, lupin cv. 'Morocco 4' maintained the highest efficiency of the photosynthetic apparatus as well as the highest number of pods, seeds per plant, height, and dry mass of shoots under drought conditions.
\end{abstract}

Additional key words: 1,000-seed mass; deficit irrigation; electron transport; legume; water stress.

\section{Introduction}

The interest in native species of the Fabaceae family has increased due to the growing demand for food in European countries and it is still increasing right now (Reckling et al. 2016). Yellow lupin and pea, used as a plant material in the presented study, are known as a valuable source of cheap feed protein (Podleśna et al. 2014) as well as complex carbohydrates, vitamins, and minerals (Dahl et al. 2012), so they are considered as one of the most important sources in human nutrition (Zaghloul et al. 2015). Pea and lupin contribute to reduction of energy costs in agriculture (Tavoletti et al. 2011) and to biodiversity in crop rotations and permanent grassland. These numerous benefits explain a need for biological progress leading to high and stable yield, also under unfavorable environmental conditions (e.g., drought), and increasing the economic importance (Bieniaszewski et al. 2012).

Legume production is increasingly threatened by various environmental stresses (Vyas 2014). In many regions of the world, climate change is resulting in extended periods of high temperatures and reduced water supply. Besides soil degradation and heat stress, drought is the abiotic factor that most adversely affects legume production (Daryanto et al. 2015). The most dangerous are water shortages at critical phases, which are periods of the greatest biomass increase as well as in the phase of generative organ formation. In legumes, drought reduces the yield by premature and insufficient seed filling as a result of flower or young pod abscissions (Juzoń et al. 2017). Numerous previous studies have demonstrated that drought stress (depending on its intensity, duration, and occurrence) eventually results in a various biochemical and physiological modifications. The plant growth and development are controlled by a multitude of physiological, biochemical, and molecular processes and photosynthesis is the key phenomenon, which contributes significantly to their course (Ashraf and Harris 2013).

In most plants, drought disrupts the process of photosynthesis mainly by altering the ultrastructure of the organelles and concentration of various pigments and metabolites including enzymes involved in this process as well as stomatal regulation (Ashraf and Harris 2013). Furthermore, drought stress is also known to inhibit photosynthesis by decreasing both leaf area and photosynthetic rate per unit leaf area (Basu et al. 2016). Chl fluorescence has been commonly known as a good indicator of the activity of photosynthesis, the efficiency of light energy conversion, and the excitation energy transfer (Komura et al. 2010). The relationship between the photosynthesis and $\mathrm{Chl}$ fluorescence emission was first described by Kautsky and Hirsch (1931). In photosynthesis,

\footnotetext{
Received 11 October 2018, accepted 24 June 2019.

${ }^{+}$Corresponding author; e-mail: e.skrzypek@ifr-pan.edu.pl

Abbreviations: Area - area over the chlorophyll $a$ fluorescence induction curve; Chl - chlorophyll; DM - dry mass; $\mathrm{ET}_{0} / \mathrm{CS}_{-}$electron transport through PSII per photosynthesizing sample cross section; $F M-$ fresh mass; $F_{v} / F_{m}-$ maximum photochemical efficiency of PSII; FWC - field water capacity; LRWC - leaf relative water content; PI - performance index of PSII; SPAD - Soil Plant Analysis Development.

Acknowledgements: This work was funded by National Science Centre, Poland (621/N-COST/09/2010/0).
} 
photochemical reactions within PSII compete with fluorescence and loss of energy in the form of heat. The electron transfer - from a Chl molecule at the reaction center of the PSII to a plastoquinone molecule within the plastoquinone conveyor - leads to photochemical fluorescence quenching. In this way, fluorescence emission can be used to monitor photosynthetic disturbances in photosynthesis reactions. However, it is important to take into account the path of energy dissipation in the form of heat, which is not always in balance with fluorescence (Baker 2008). Study of Lichtenthaler et al. (1986) showed that plants (depending on the species) lost up to $10 \%$ of the absorbed light energy in the form of $\mathrm{Chl}$ fluorescence. Fluorescence can be successfully used in the study on the effects of environmental stresses, such as water deficit, low temperature or heavy metals (Kalaji et al. 2016). In fluorescence measurements, the fluorescence parameters of Chl $a$ are taken into account, which are the indicators of the state of the photosynthetic apparatus, showing changes in its functioning and the course of photosynthesis, while also allowing to locate the most important damage region (Murchie and Lawson 2014). Understanding how plants respond to water deficit can play a principal role in stabilizing crop performance under drought conditions (Batra et al. 2014). Improvement of plant responses to water shortages remains an open field of research, namely, in the legume family, where previous efforts have not produced the desired results for crops (Jeuffroy and Ney 1997).

The aim of the study was to evaluate the effects of drought on chlorophyll $a$ fluorescence parameters of yellow lupin (Lupinus luteus L.) and pea (Pisum sativum L.). To indicate the influence of drought on the changes of Chl $a$ fluorescence parameters, leaf relative water content and $\mathrm{Chl}$ concentration indicator in SPAD units were correlated with yield components.

\section{Materials and methods}

Plant material and growth conditions: Two genera of legume plants were tested: yellow lupin (Lupinus luteus L.) and pea (Pisum sativum L.). Within each genus, two cultivars were subjected to drought stress; in yellow lupin, 'Morocco 4' (tolerant) and 'Taper' (sensitive), and in pea, 'Wenus' (tolerant) and 'SZD165' (sensitive). Preliminary assessment of drought susceptibility was performed on the base of the changes in protein and phenolics content in the previous experiment (Juzoń et al. 2013). Seeds were purchased from Poznańska Plant Breeding Ltd. Co. (Tulce, Poland) and sown into a 3.6-kg mixture of horticultural soil (loamy soil, $85 \%)$ and loam (15\%), peat, and sand (1:1:1, $\mathrm{v} / \mathrm{v} / \mathrm{v})$ in pots $(50 \times 20 \times 20 \mathrm{~cm})$. The plants were grown in plastic pots under an open-air vegetation tunnel protected from rain by gardening foil during spring-summer period (April-September). The experiments were conducted at the Institute of Plant Physiology, Polish Academy of Science $\left(50^{\circ} 47^{\prime} \mathrm{N}, 19^{\circ} 50^{\prime} \mathrm{E}\right)$, Kraków, Poland.

Scheme of the experiment: When the plants developed five to six leaves, irrigation was withheld for half of the tested plants (60 plants) for $14 \mathrm{~d}$ to reach $25 \%$ of field water capacity (FWC). These plants were subjected to soil drought $(25 \% \mathrm{FWC})$ for the next $14 \mathrm{~d}$. At the same time plants (60 plants) from control treatment were irrigated up to $70 \%$ FWC. After $14 \mathrm{~d}$ of treatments [drought (D)/ control (C)], all plants (120) were irrigated up to 70\% FWC to allow further analysis of the yield components. During the experiment, the water content in soil was controlled gravimetrically, including the mass of plants growing in the pots, and by using a moisture meter MO750 (Extech Instruments Corporation, USA).

Leaf relative water content (LRWC) was determined at 1 and $14 \mathrm{~d}$ of drought according to Barrs and Weatherley (1962) using the following formula: LRWC [\%] = $[(\mathrm{FM}-\mathrm{DM}) /(\mathrm{TM}-\mathrm{DM})] \times 100$, where FM, DM, and TM represent fresh mass, dry mass, and turgid mass, respectively. Samples were collected from the second fully developed leaf from each independent plant.

Chl concentration: The Chl concentration indicator in SPAD units was determined by photometric method using SPAD 502 device (Konica Minolta, Japan) based on the leaf greenness index. By measuring the wavelength of $650 \mathrm{~nm}$, the amount of light absorbed by the Chl was determined. In addition, light was measured at a wavelength of $940 \mathrm{~nm}$ which is absorbed by the rest of the structure. This was used to correct the result calculated by the microprocessor and given in contractual units, called SPAD readings (with maximum at 60 units). SPAD readings are directly proportional to the Chl content (Konica Minolta 2009). The Chl concentration indicator in SPAD units was measured twice: at 1 and $14 \mathrm{~d}$ of drought. The measurements were taken in the middle part of the second or third fully developed leaf (counting from the youngest leaf) from each independent plant.

Chl $\boldsymbol{a}$ fluorescence kinetics parameters were measured by using a Handy PEA fluorometer (Hansatech, King's Lynn, UK). The measurements were made on the same leaves on which the Chl concentration indicator in SPAD unit was measured previously at 1 and $14 \mathrm{~d}$ of drought. The leaf fragments were shaded with clips for about $20 \mathrm{~min}$ and then the measurement was taken. It was initiated by illuminating the leaf fragment with saturated light [intensity of 90 units $=5,400 \mu \mathrm{mol}$ (photon) $\mathrm{m}^{2} \mathrm{~s}^{-1}$, illumination time $0.9 \mathrm{~s}$ ] to determine the maximum fluorescence $\left(\mathrm{F}_{\mathrm{m}}\right)$ and calculate the maximum photochemical potential $\left(\mathrm{F}_{\mathrm{v}} / \mathrm{F}_{\mathrm{m}}\right)$. Then, actinic light was switched on automatically [25 units $=1,500 \mu \mathrm{mol}$ (photon) $\mathrm{m}^{-2} \mathrm{~s}^{-1}$ ] for a period of $270 \mathrm{~s}$. When it was switched off, the leaf light was emitted by a diode emitting light in the far red range of about $15 \mathrm{~W} \mathrm{~m}^{-2}$. On the basis of Chl $a$ fluorescence measurements, the following parameters were calculated and analyzed: $\mathrm{F}_{\mathrm{v}} / \mathrm{F}_{\mathrm{m}}$ - maximum photochemical efficiency of PSII; Areaarea over the $\mathrm{Chl} a$ fluorescence induction curve; $\mathrm{ET}_{0} / \mathrm{CS}-$ electron transport through PSII of photosynthesizing sample at $t=0$; and PI - performance index of PSII.

Yield component analyses: To estimate the impact of 
drought on yield of tested plants, the number of pods per plant, the number of seeds per pod, number of seeds per plant, dry mass (DM) of seeds per plant, 1,000-seeds mass, height of plant, and the dry mass (DM) of shoots were determined.

Statistical analysis: A completely randomized design was used to perform the experiment, which consisted of 60 well-watered plants as control and 60 plants subjected to drought. The results presented in figures constitute the mean values \pm standard error based on 15 plants as replicates. Data were analyzed using two-way analysis of variance $(A N O V A)$ with a statistical software package STATISTICA 10.0 (Stat-Soft, USA). A two-way ANOVA was designed to assess the interrelationship of two independent variables (cultivar and treatment) on a dependent variable (LRWC, $\mathrm{SPAD}, \mathrm{F}_{\mathrm{v}} / \mathrm{F}_{\mathrm{m}}$, Area, $\mathrm{ET}_{0} / \mathrm{CS}, \mathrm{PI}$, number of pods per plant, number of seeds per pod, number of seeds per plant, DM of seeds per plant, 1,000-seed mass, height of plant, and the DM of shoots. Duncan's multiple range test at the 0.05 probability level was used to determine the significance of differences between cultivars, which was marked with different letters. Student's $t$-test at the 0.05 probability level was also used to compare the average values for each treatment. Additionally, Pearson's linear correlation matrix was calculated between the selected parameters.

\section{Results}

Leaf relative water content: A significant decrease in LRWC was shown in tested plants under drought comparing with control conditions (Fig.1A). The observed decline was similar in yellow lupin and pea plants. The LRWC in yellow lupin cv. 'Morocco 4' was reduced by $5.4 \%(\mathrm{C} 1-91.7 \%$; D1 $-86.8 \%)$ on the $1^{\text {st }}$ day and by $8.2 \%(\mathrm{C} 14-90.1 \% ; \mathrm{C} 14-82.7 \%)$ on the $14^{\text {th }}$ day of drought. In cv. 'Taper', a greater decrease was noted: $7.3 \%$ $(\mathrm{C} 1-90.9 \%$; D1 $-84.3 \%)$ on the $1^{\text {st }}$ and $9.4 \%(\mathrm{C} 14-$ $88.0 \%$; D14 $-79.7 \%$ ) on the $14^{\text {th }}$ day. The soil drought stress reduced LRWC also in pea plants; the decline in cv. 'Wenus' was by $3.1 \%$ (C1-91.2\%; D1 - 88.4\%) on the $1^{\text {st }}$ day (not statistically significant) and by $7.9 \%$ (C14 $90.8 \%$; D14 $-83.6 \%$ ) on the $14^{\text {th }}$ day, while in 'SZD165', it was $4.2 \%(\mathrm{C} 1-92.4 \%$; D1 - 88.5\%) and 8.1\% (C14 $90.8 \%$; D14-83.5\%), respectively. The calculated average for each species revealed that on the $14^{\text {th }}$ day of drought, pea was characterized by the greater decrease of water content in leaves compared to yellow lupin.

Chl concentration indicator in SPAD values did not show significant changes considering all cultivars (Fig. 1B). However, the average values calculated only for pea revealed a decrease of SPAD in leaves both on the $1^{\text {st }}$ (by $c a .8 \%$ ) and $14^{\text {th }}$ (by $c a .3 \%$ ) day of drought. Moreover, leaves of pea were characterized by an increase in Chl (SPAD) along with the age of plants, both under control and drought conditions. A similar reaction, however, was not observed in yellow lupin.

Chl $\boldsymbol{a}$ fluorescence kinetics parameters: Tested parameters showed ambiguous response to soil drought stress conditions (Fig. 2). The decline in the value of $\mathrm{F}_{\mathrm{v}} / \mathrm{F}_{\mathrm{m}}$ was found in yellow lupin and pea plants subjected to soil drought stress (Fig. 2A). In yellow lupin cv. 'Morocco 4',

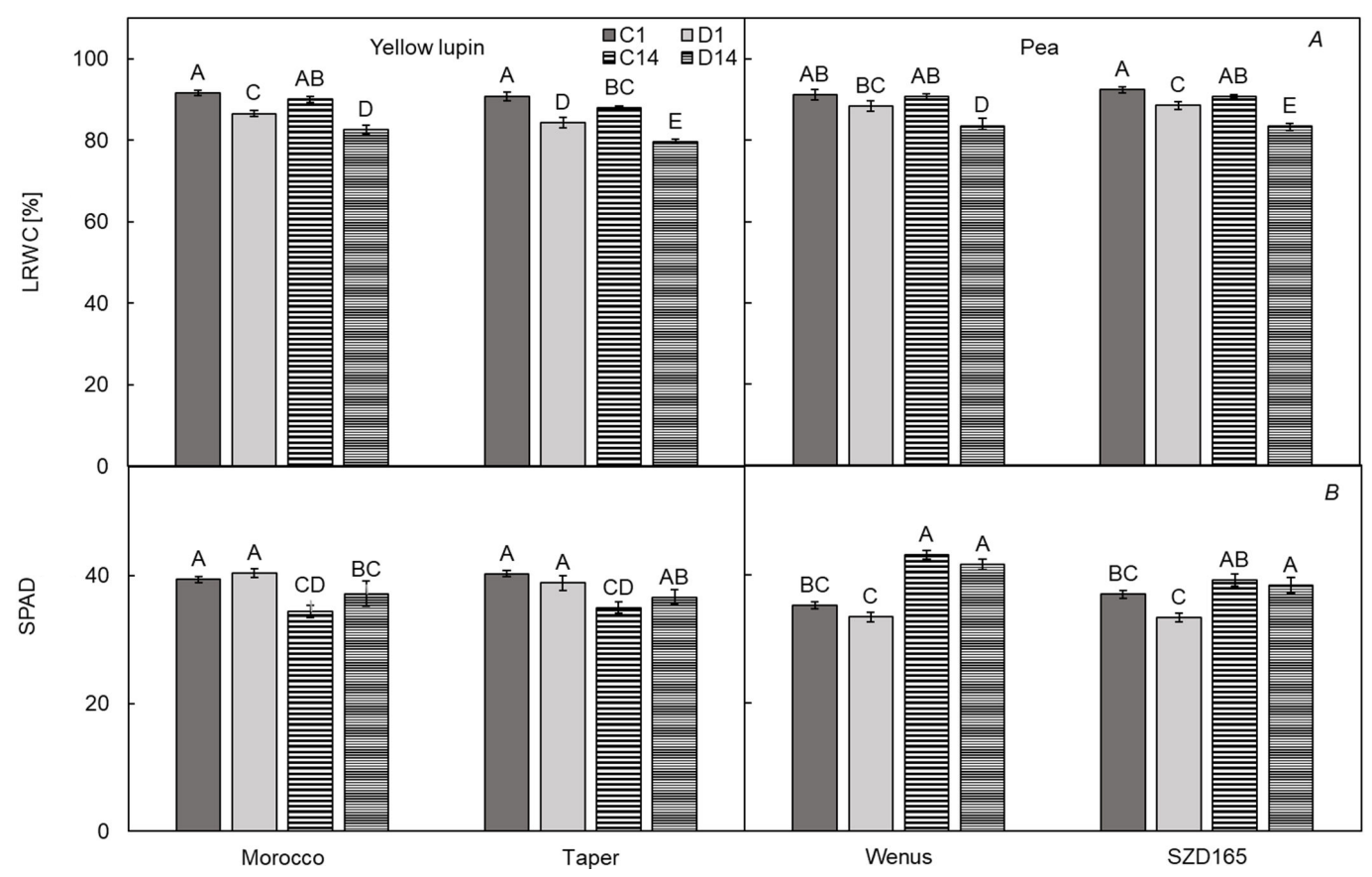

Fig. 1. The effect of soil drought stress on the leaf relative water content (LRWC) $(A)$ and chlorophyll concentration indicator in SPAD units $(B)$ in yellow lupin (Lupinus luteus L.), cvs. 'Morocco 4' and 'Taper', and pea (Pisum sativum L.), cvs. 'Wenus' and 'SZD165', leaves on $1^{\text {st }}(\mathrm{C} 1, \mathrm{D} 1)$ and $14^{\text {th }}(\mathrm{C} 14, \mathrm{D} 14)$ day of drought. Values are means $\pm \mathrm{SE}, n=15$. Values marked with different letters are significantly different at $\alpha \leq 0.05$ according to the Duncan's multiple test. C - control ( $70 \%$ FWC); D - drought (25\% FWC). 


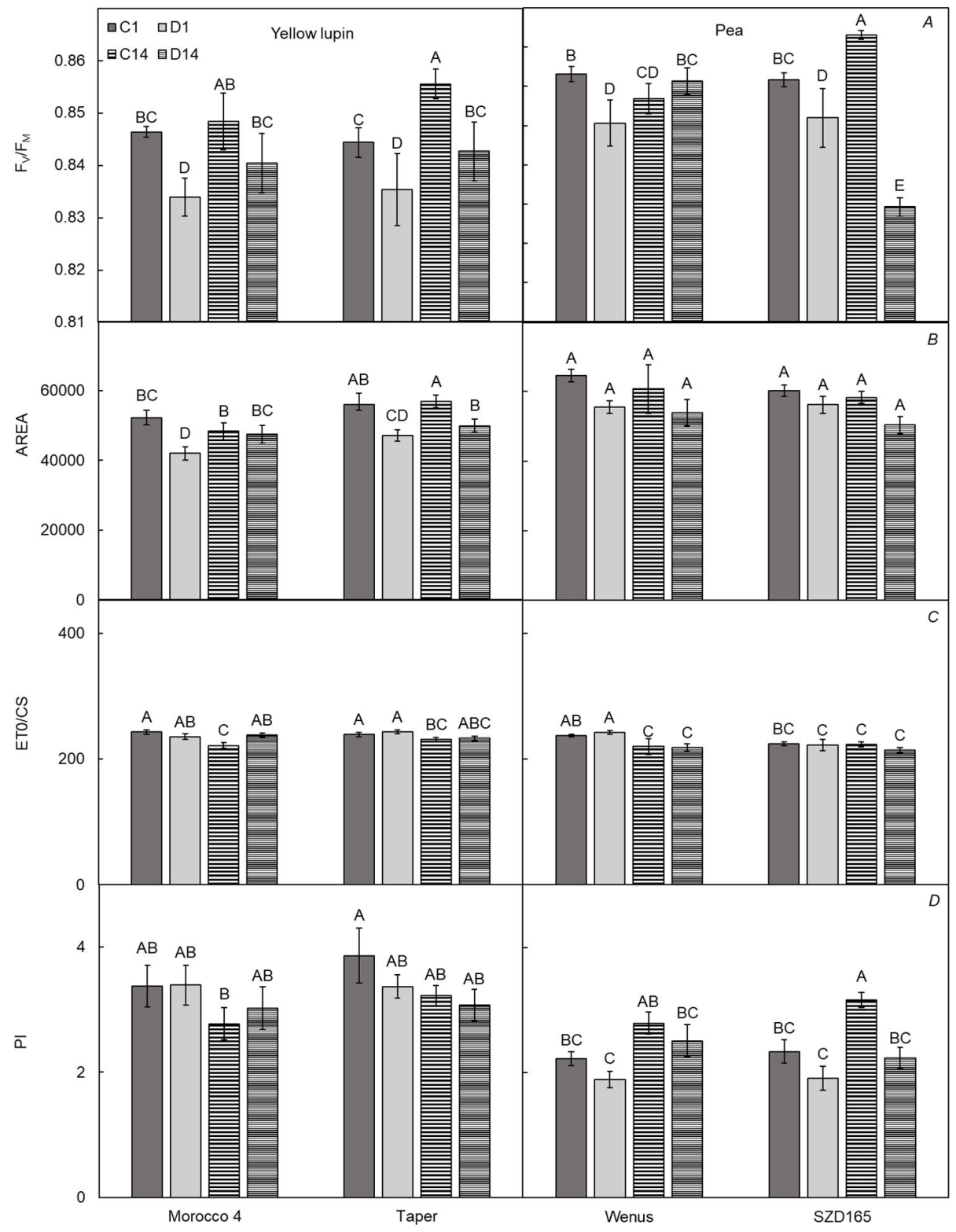

Fig. 2. The effect of soil drought stress on chlorophyll $a$ fluorescence kinetic parameters: maximum photochemical efficiency of PSII $\left(\mathrm{F}_{\mathrm{v}} / \mathrm{F}_{\mathrm{m}}\right)(A)$; area over the chlorophyll $a$ fluorescence induction curve (Area) $(B)$; electron transport through PSII of photosynthesizing sample at $t=0$ $\left(\mathrm{ET}_{0} / \mathrm{CS}\right)(C)$; and performance index of PSII (PI) $(D)$ in yellow lupin (Lupinusluteus), cvs. 'Morocco4'and 'Taper', and pea (Pisum sativum), cvs. 'Wenus' and 'SZD165', leaves on the $1^{\text {st }}(\mathrm{C} 1, \mathrm{D} 1)$ and the $14^{\text {th }}(\mathrm{C} 14$, D14) day of drought. Values are means $\pm \mathrm{SE}, n=15$. Values marked with different letters are significantly different at $\alpha \leq 0.05$ according to the Duncan's multiple test. C - control (70\% FWC); D - drought $(25 \%$ FWC). a decrease of $F_{v} / F_{m}$ was similar at both measurement days and it was approximately $1 \%(\mathrm{C} 1-0.847$; D1 -0.834 ; C14 - 0.848; D14 - 0.841) compared with control conditions. Whereas in $\mathrm{cv}$. 'Taper' on $1^{\text {st }}$ day, the $\mathrm{F}_{\mathrm{v}} / \mathrm{F}_{\mathrm{m}}$ decreased by $1.2 \%(\mathrm{C} 1-0.845 ; \mathrm{D} 1-0.835)$ and on the $14^{\text {th }}$ day, it decreased by $1.5 \%(\mathrm{C} 14-0.856 ; \mathrm{D} 14-0.843)$. Pea cultivars showed greater differentiation: cv. 'Wenus' was characterized by a statistically important decline of this parameter only on the $1^{\text {st }}$ day of drought. Furthermore, in 'SZD165' on the $1^{\text {st }}$ day, a decrease of $1.2 \%$ (C1 $0.852 ; \mathrm{D} 1-0.842$ ) was noted, while on the $14^{\text {th }}$ day, it increased by $5.1 \%(\mathrm{C} 14-0.863$; D14 - 0.819). Generally, soil drought stress reduced $\mathrm{F}_{\mathrm{v}} / \mathrm{F}_{\mathrm{m}}$ in yellow lupin plants by $1.2 \%$ regardless of the day of measurement. In pea plants, the decrease on the $14^{\text {th }}$ day was $c a$. 2-fold greater $(3.0 \%)$ than that on the $1^{\text {st }}$ day of drought $(1.3 \%)$.

The soil drought stress caused the decline also in the
Area (Fig. 2B). The greatest reduction was noted on the $1^{\text {st }}$ day in yellow lupin cv. 'Morocco 4' - by $19.4 \%$ (C1 52,127 ; D1 - 42,003) compared with control conditions. In cv. 'Taper', the observed decrease was slightly lower - of $15.8 \%(\mathrm{C} 1-56,012 ; \mathrm{D} 1-47,140)$ on the $1^{\text {st }}$ day and of $12.3 \%(\mathrm{C} 14-56,892$; D14 $-49,894)$ on the $14^{\text {th }}$ day of drought. Also pea plants showed reduction of this value compared with control conditions - above 10\% (C1 64,545; D1 - 55,479; C14 - 60,687; D14 - 53,958) in cv. 'Wenus' on both measurement days. In 'SZD165', the decline of Area was approximately 2 -fold greater on the $14^{\text {th }}$ day $(13.6 \%$; C14 $-58,303 ; \mathrm{D} 14-50,373)$ than that on the $1^{\text {st }}$ day of drought $(6.7 \%$; $1-60,226 ; \mathrm{D} 1-56,170)$. In general, the tested species were characterized by the opposite trend: yellow lupin showed a greater Area decline on the $1^{\text {st }}$ day $(17.6 \%)$, while pea on the $14^{\text {th }}$ day of drought $(12.3 \%)$, compared with control conditions. 
The electron transport through PSII $\left(\mathrm{ET}_{0} / \mathrm{CS}\right)$ mostly did not show significant changes (Fig. 2C). The observed decreasing tendency did not exceed $4 \%$ compared to control. However, in yellow lupin cv. 'Morocco 4', the statistically important increase of $c a$. 7\% (C14-221.7; D1 238.0) was noted. There was also no significant decrease for each of the tested genera.

Soil drought stress influenced the performance index of PSII (PI) (Fig. 2D). Yellow lupin cv. 'Morocco 4' showed a significant increase of $7.2 \%(\mathrm{C} 14-2.8$; D14 - 3.0) on the $14^{\text {th }}$ day, while cv. 'Taper' was characterized by a decline of PI value both on the $1^{\text {st }}$ and $14^{\text {th }}$ day of drought 12.7\% (C1 - 3.9; D1 - 3.4) and 3.1\% (C14 - 3.2; D14 3.1 , respectively. In pea cv. 'Wenus', a decrease of $9.1 \%$ $(\mathrm{C} 1-2.2 ; \mathrm{D} 1-2.0)$ on the $1^{\text {st }}$ day and of $10.7 \%(\mathrm{C} 1-2.8$; D $1-2.5)$ on the $14^{\text {th }}$ day of drought was noticed. Plants of 'SZD165' showed greater PI reduction: $13.1 \%(\mathrm{C} 1-2.3$; $\mathrm{D} 1-2.0)$ and $31.1 \%(\mathrm{C} 14-3.2 ; \mathrm{D} 14-2.2)$ on the $1^{\text {st }}$ and $14^{\text {th }}$ day, respectively. Generally, PI in yellow lupin did not change significantly under drought conditions, while in pea plants, a decline of $17.4 \%$ on the $1^{\text {st }}$ day and $20 \%$ on the $14^{\text {th }}$ day was observed.

Yield components: Soil drought stress reduced most of the tested yield components both in yellow lupin and pea plants and the majority of these changes were statistically significant (Table 1). However, in yellow lupin cultivars, fewer parameters showed a significant decrease in value under drought conditions compared to pea cultivars. The 1,000 -seed mass was reduced in cv. 'Morocco 4' by $29 \%$ (C - $154.4 \mathrm{~g}$; D - 109.6 g) and in cv. 'Taper' by 60\% (C $275.0 \mathrm{~g} ; \mathrm{D}-109.5 \mathrm{~g})$, while DM of shoots decreased by $53 \%(\mathrm{C}-5.4 \mathrm{~g} ; \mathrm{D}-2.5 \mathrm{~g})$ and $60 \%(\mathrm{C}-2.8 \mathrm{~g} ; \mathrm{D}-$ $1.1 \mathrm{~g})$, respectively. Furthermore, cv. 'Morocco 4' was characterized by a decline of DM of seeds $(48 \% ; \mathrm{C}-3.1 \mathrm{~g}$; $\mathrm{D}-1.6 \mathrm{~g})$, while in cv. 'Taper', a decline of the number of seeds per pod $(25 \% ; \mathrm{C}-3.2 ; \mathrm{D}-2.4)$ and the height of plants $(48 \% ; \mathrm{C}-69.1 \mathrm{~cm} ; \mathrm{D}-35.9 \mathrm{~cm})$ was observed. Pea plants were characterized by the reduction of most tested yield components. In both cultivars, soil drought caused a decrease of the number of seeds per plant: in 'Wenus' by $38 \%(C-17.5 ; \mathrm{D}-10.9)$ and in 'SZD165' by $18 \%(\mathrm{C}-17.3$; $\mathrm{D}-14.1)$. A reduction in DM of seeds in 'Wenus' (53\%: $\mathrm{C}-4.9 ; \mathrm{D}-2.3)$ and in 'SZD 165 ' $(45 \% ; \mathrm{C}-4.2 ; \mathrm{D}-2.3)$ was observed. Also a 1,000-seed mass showed a decrease under drought conditions - in 'Wenus' by $23 \%$ (C $282.8 \mathrm{~g}$; D-217.0 g) and in 'SZD165' by $32 \%(\mathrm{C}-237.8 \mathrm{~g}$; $\mathrm{D}-161.2 \mathrm{~g})$. Furthermore, a decrease in height of plants was found: by $47 \%(\mathrm{C}-88.4 \mathrm{~cm}$; D $-46.6 \mathrm{~cm})$ in 'Wenus' and by $39 \%(C-66.0 \mathrm{~cm}$; D - $40.1 \mathrm{~cm})$ in 'SZD165', as well as a reduction in DM of shoots, i.e., by $64 \%(\mathrm{C}-5.5 \mathrm{~g}$; $\mathrm{D}-2.0 \mathrm{~g})$ in 'Wenus' and by $49 \%(\mathrm{C}-3.7 \mathrm{~g} ; \mathrm{D}-1.9 \mathrm{~g})$ in 'SZD165'. Moreover, in cv. 'Wenus', a decline of the number of seeds per pod by $26 \%(C-3.8$; D -2.8$)$ was noted. Generally, two tested genera were characterized by a decrease of 6 per 7 yield component. Yellow lupin did not show significant change in the number of seeds per pod while pea did not change the number of seeds per plant. The decline of the rest of the tested yield components varied from $c a$. 20 to $c a$. $60 \%$, compared with control conditions. The highest reduction was noted for DM of seeds $(48 \%$ in yellow lupin and 50\% in pea) and DM of shoots (56 and $57 \%$, respectively). The components, which showed the greatest variation between these two genera, were: the number of seeds per plant (reduced by $36 \%$ in yellow lupin and by $28 \%$ in pea) and 1,000-seed mass (reduced by 49 and $27 \%$, respectively).

A number of significant correlations have been shown between LRWC, Chl concentration indicator in SPAD units, Chl $a$ fluorescence kinetics parameters, and yield components (Table 2). The majority of recorded correlation was significant at $p=0.001$. The LRWC showed a low negative correlation with the Chl $a$ fluorescence parameters and 1,000-seed mass, plant height, and DM of shoot. All tested Chl $a$ fluorescence parameters were correlated with Chl concentration (SPAD) and almost full correlation (0.9-1.0) was found between SPAD and $\mathrm{F}_{\mathrm{v}} / \mathrm{F}_{\mathrm{m}}$ as well as $\mathrm{ET}_{0} / \mathrm{CS}$. The number of seeds per pod and DM of seeds showed moderate and high negative correlations with the Chl $a$ fluorescence parameters, while the other yield components demonstrated positive correlations.

\section{Discussion}

LRWC provides a measurement of the leaf 'water deficit', and may indicate a degree of stress expressed under drought and heat conditions. This parameter integrates leaf water potential $(\psi)$ with the effect of osmotic adjustment

Table 1. The effect of soil drought stress on the yield components of yellow lupin (Lupinus luteus L.) and pea (Pisum sativum L.). Values are means, $n=60$. For a given yield component and for each species, values marked with different letters are significantly different at $\alpha \leq 0.05$ according to Duncan's multiple tests. C - control (70\% FWC); D - drought ( $25 \%$ FWC); DM - dry mass.

\begin{tabular}{|c|c|c|c|c|c|c|c|c|c|c|c|c|c|c|}
\hline \multirow[t]{2}{*}{ Cultivar } & \multicolumn{2}{|c|}{ Pods per plant } & \multicolumn{2}{|c|}{ Seeds per pod } & \multicolumn{2}{|c|}{ Seeds per plant } & \multicolumn{2}{|c|}{ Seed DM [g] } & \multicolumn{2}{|c|}{1,000 -seed mass $[\mathrm{g}]$} & \multicolumn{2}{|c|}{ Plant height $[\mathrm{cm}]$} & \multicolumn{2}{|c|}{ Shoot DM [g] } \\
\hline & $\mathrm{C}$ & $\mathrm{D}$ & $\mathrm{C}$ & $\mathrm{D}$ & $\mathrm{C}$ & $\mathrm{D}$ & $\mathrm{C}$ & $\mathrm{D}$ & $\mathrm{C}$ & $\mathrm{D}$ & $\mathrm{C}$ & $\mathrm{D}$ & $\mathrm{C}$ & $\mathrm{D}$ \\
\hline \multicolumn{15}{|c|}{ Yellow lupine } \\
\hline Morocco 4 & $8.7^{\mathrm{a}}$ & $7.2^{\mathrm{ab}}$ & $2.8^{\mathrm{a}}$ & $2.6^{\mathrm{a}}$ & $25.0^{\mathrm{a}}$ & $18.4^{\mathrm{ab}}$ & $3.1^{\mathrm{a}}$ & $1.6^{\mathrm{b}}$ & $154.4^{\mathrm{a}}$ & $109.6^{\mathrm{a}}$ & $62.7^{\mathrm{ab}}$ & $53.2^{\mathrm{b}}$ & $5.4^{\mathrm{a}}$ & $2.5^{\mathrm{b}}$ \\
\hline Taper & $5.4^{\mathrm{bc}}$ & $3.8^{\mathrm{c}}$ & $3.2^{\mathrm{a}}$ & $2.4^{\mathrm{a}}$ & $18.8^{\mathrm{ab}}$ & $9.8^{\mathrm{b}}$ & $1.5^{\mathrm{b}}$ & $0.9^{\mathrm{b}}$ & $275.0^{\mathrm{a}}$ & $109.5^{\mathrm{a}}$ & $69.1^{\mathrm{a}}$ & $35.9^{c}$ & $2.8^{\mathrm{a}}$ & $1.1^{\mathrm{c}}$ \\
\hline \multicolumn{15}{|l|}{ Pea } \\
\hline Wenus & $4.7^{\mathrm{a}}$ & $4.0^{\mathrm{a}}$ & $3.8^{\mathrm{a}}$ & $2.8^{\mathrm{b}}$ & $17.5^{\mathrm{a}}$ & $10.9^{\mathrm{b}}$ & $4.9^{\mathrm{a}}$ & $2.3^{\mathrm{b}}$ & $282.8^{\mathrm{a}}$ & $217.0^{\mathrm{b}}$ & $88.4^{\mathrm{a}}$ & $46.6^{c}$ & $5.5^{\mathrm{a}}$ & $2.0^{\mathrm{c}}$ \\
\hline SZD165 & $4.1^{\mathrm{a}}$ & $5.5^{\mathrm{a}}$ & $4.3^{\mathrm{a}}$ & $2.6^{\mathrm{b}}$ & $17.3^{\mathrm{a}}$ & $14.1^{\mathrm{ab}}$ & $4.2^{\mathrm{a}}$ & $2.3^{\mathrm{b}}$ & $237.8^{\mathrm{b}}$ & $161.2^{\mathrm{c}}$ & $66.0^{\mathrm{b}}$ & $40.1^{\mathrm{c}}$ & $3.7^{\mathrm{b}}$ & $1.9^{c}$ \\
\hline
\end{tabular}


Table 2. Pearson's linear correlation matrix between: leaf relative water content (LRWC) in leaves, chlorophyll concentration indicator in SPAD units (SPAD), chlorophyll $a$ fluorescence kinetics parameters $\left(\mathrm{F}_{\mathrm{v}} / \mathrm{F}_{\mathrm{m}}\right.$, Area, $\left.\mathrm{ET}_{0} / \mathrm{CS}, \mathrm{PI}\right)$ and yield components (number of pods per plant, number of seeds per pod, number of seeds per plant, DM of seeds; 1,000-seed mass, plant height, DM of shoots) of yellow lupin (Lupinus luteus L.) and pea (Pisum sativum L.). Area - area over the chlorophyll a fluorescence induction curve; DM - dry mass; $\mathrm{ET}_{0} / \mathrm{CS}$ - electron transport through PSII per photosynthesizing sample cross section; $\mathrm{F}_{\mathrm{v}} / \mathrm{F}_{\mathrm{m}}-$ maximum photochemical efficiency of PSII; PI - performance index of PSII.

\begin{tabular}{|c|c|c|c|c|c|c|c|c|c|c|c|c|c|c|}
\hline & & 1 & 2 & 3 & 4 & 5 & 6 & 7 & 8 & 9 & 10 & 11 & 12 & 13 \\
\hline 1 & LRWC & 1 & & & & & & & & & & & & \\
\hline 2 & SPAD & -0.34 & 1 & & & & & & & & & & & \\
\hline 3 & $\mathrm{~F}_{\mathrm{v}} / \mathrm{F}_{\mathrm{m}}$ & -0.25 & 0.95 & 1 & & & & & & & & & & \\
\hline 4 & Area & -0.16 & 0.87 & 0.93 & 1 & & & & & & & & & \\
\hline 5 & $\mathrm{ET}_{0} / \mathrm{CS}$ & -0.24 & 0.92 & 0.98 & 0.93 & 1 & & & & & & & & \\
\hline 6 & PI & -0.22 & 0.83 & 0.85 & 0.80 & 0.83 & 1 & & & & & & & \\
\hline 7 & Pods per plant & 0.16 & 0.26 & 0.29 & 0.29 & 0.27 & 0.31 & 1 & & & & & & \\
\hline 8 & Seeds per pod & 0.26 & -0.53 & -0.56 & -0.50 & -0.54 & -0.48 & 0.02 & 1 & & & & & \\
\hline 9 & Seeds per plant & 0.15 & 0.56 & 0.60 & 0.62 & 0.57 & 0.53 & 0.72 & -0.33 & 1 & & & & \\
\hline 10 & Seed DM [g] & 0.20 & -0.59 & -0.61 & -0.57 & -0.60 & -0.52 & 0.01 & 0.73 & -0.43 & 1 & & & \\
\hline 11 & 1,000 -seed mass $[\mathrm{g}]$ & -0.39 & 0.67 & 0.64 & 0.58 & 0.59 & 0.46 & 0.05 & -0.48 & 0.31 & -0.51 & 1 & & \\
\hline 12 & Plant height $[\mathrm{cm}]$ & -0.41 & 0.39 & 0.31 & 0.14 & 0.27 & 0.34 & -0.01 & -0.41 & 0.17 & -0.43 & 0.47 & 1 & \\
\hline \multirow[t]{4}{*}{13} & Shoot DM [g] & -0.15 & 0.69 & 0.70 & 0.67 & 0.66 & 0.55 & 0.44 & -0.46 & 0.68 & -0.51 & 0.73 & 0.37 & 1 \\
\hline & correlation & \multicolumn{2}{|c|}{ negative } & & & \multicolumn{3}{|c|}{ positive } & & & & & & \\
\hline & & $p=0.05$ & 0.01 & 0.001 & & 0.05 & 0.01 & 0.001 & & & & & & \\
\hline & & - & - & & & & & & & & & & & \\
\hline
\end{tabular}

as a measurement of plant water status. Lazacano-Ferrat and Lovat (1999) subjected bean plant to drought stress and after 10,14, and $18 \mathrm{~d}$ without watering, they evaluated LRWC of stem and found it was significantly lower than that of control plants. Also Ramos et al. (2003) stated that LRWC of bean leaves under drought stress decreased. Depending on the reduction of LRWC, water stress can be divided into mild (LRWC decreases by $8-10 \%$ ), moderate (10-20\%), and severe (over 20\%) (Hsiao 1973). According to this classification, the soil drought applied in our experiment caused mild water stress because LRWC reduction did not exceed $10 \%$. In the presented study, a greater LRWC decline was observed on the $14^{\text {th }}$ day of drought (compared to the $1^{\text {st }}$ day). Moreover, deeper reduction was noticed in less tolerant cultivars - 'Taper' (yellow lupin) and 'SZD165' (pea). As it was shown in previous studies, legumes are able to maintain their leaf water content and avoid tissue dehydration during mild drought by controlling their stomatal conductance and closure (Pinheiro et al. 2001). However, such closure, consequently, can lead to a decrease in internal $\mathrm{CO}_{2}$ concentrations, which eventually limits photosynthesis and shoot growth (Chaves et al. 2009). According to Medrano et al. (2002), drought stress, particularly at its mild intensity, can inhibit leaf photosynthesis and stomatal conductance in most green plants. Furthermore, various environmental stressors, including drought, have been reported to reduce the contents of photosynthetic pigments (Ashraf and Harris 2013). They also lead to the deterioration of thylakoid membranes (Anjum et al. 2011). Under drought conditions, the decrease in Chl is a commonly observed phenomenon (Mafakheri et al.
2010). In presented studies, the Chl content in leaves was measured using the photometric method which determines the Chl concentration indicator in SPAD units. Cassol et al. (2008) showed in maize (Zea mays L.), cucumber (Cucumis sativus L.), and radish (Raphanus sativus L.) that the $\mathrm{Chl}$ index was linear and positively correlated with the Chl content of the examined plants. However, the reading of the instrument cannot be regarded as the absolute content of the $\mathrm{Chl}$ in the leaves. The relationship between $\mathrm{Chl}$ content and greenness index is influenced by the nonuniform distribution of $\mathrm{Chl}$ molecules in the leaf due to the structural organization of the granules in chloroplasts, the amount of chloroplasts in the cell, and cells in the tissue. These patterns may vary widely between species and/or by the nonuniform distribution of radiation through the leaf surface and different scattering and reflection of radiation (Cassol et al. 2008). Despite the lack of any significant changes in the SPAD values between the tested cultivars generally, statistical differences were observed in pea plants, where the decline of SPAD after drought treatment was observed. Some studies showed an enhanced accumulation of $\mathrm{Chl}$ under drought stress as in Medicago sativa (Estill et al. 1991). Under drought conditions, Ashraf and Karim (1991) reported both an increase and decrease of $\mathrm{Chl}$ depending on the tested cultivars of black gram (Vigna mungo). They suggested that it may be due to the variation in Chl synthesis among the cultivars mediated by the variation in the activities of specific enzymes involved in the biosynthesis of Chl. Therefore, it seems that the SPAD should not be treated as an independent indicator of drought-stress tolerance, especially, under mild drought stress, when it may not 
show any significant changes in value.

Photosynthetic pigments, including $\mathrm{Chl}$, are believed to be damaged by stress factors resulting in a reduced lightabsorbing efficiency of both photosystems (PSI and PSII) as well as a reduced photosynthetic capacity. Light energy absorbed by $\mathrm{Chl}$ is transformed into $\mathrm{Chl}$ fluorescence (Maxwell and Johnson 2000). In vivo Chl $a$ fluorescence may be used as a direct indicator of photosynthetic activity. Particularly in plants exposed to stress factors its measurement - convenient and noninvasive - gives a valuable insight into the exploitation of the excitation energy by PSII, and indirectly by other protein complexes of the thylakoid membranes (Roháček 2002). Recent improvements in measurement techniques have made the fluorescence method an important tool in stress physiology and environmental research (Kościelniak et al. 2006). The functional state of photosynthetic apparatus is a useful physiological indicator to study the sensibility of plants to environmental abiotic stress, including drought (Strasser et al. 2004, Tsonev et al. 2014). Similarly to others stresses, drought is known to alter the Chl $a$ fluorescence kinetics and hence to damage the PSII reaction center. A number of experiments conducted in vivo have shown that drought stress causes considerable damage to the oxygenevolving center coupled with PSII (Kawakami et al. 2009) as well as degradation of D1 polypeptide leading to the inactivation of the PSII reaction center (Liu et al. 2006). In the presented studies, several Chl fluorescence parameters were examined to estimate their changes under applied soil drought conditions. One of them was the maximum photochemical efficiency of PSII $\left(\mathrm{F}_{\mathrm{v}} / \mathrm{F}_{\mathrm{m}}\right)$. The $F_{v} / F_{m}$ is a measure of light recovery efficiency in primary photosynthesis reactions, and its value is proportional to the quantum yield of PSII photochemical reactions (Lawson et al. 2002). Under optimal conditions, this parameter achieves 0.832 in vascular plants (Björkman and Demmig 1987). According to some authors, the reduction of $\mathrm{F}_{\mathrm{v}} / \mathrm{F}_{\mathrm{m}}$ indicates that the tested plants were exposed to stressors that damaged the PSII function, reducing the efficiency of electron transport. In our studies, the decline of $F_{v} / F_{m}$ was noted, both in yellow lupin and pea plants, despite the fact that, in most cases, the values were higher than 0.832 (regardless of growing conditions, drought or control). The obtained results indicate that applied soil drought influenced the photochemical efficiency of PSII of tested plants, although the decline did not exceed a few percent in value. Also in the studies of Marcińska et al. (2017), the $\mathrm{F}_{\mathrm{v}} / \mathrm{F}_{\mathrm{m}}$ parameter was the most sensitive to water deficit in the soil, despite the fact that it did not provide complete information on photochemical properties of PSII. However, the literature gives examples of studies where stress did not alter this parameter. For example, in soybean, the $F_{v} / F_{m}$ and electron transport velocity did not change due to water stress (Ohashi et al. 2006). Also Qiu and Lu (2003) as well as Lu and Zhang (1999) reported no $F_{v} / F_{m}$ decrease under stress conditions. According to Antonkiewicz and Rapacz (2006), $\mathrm{F}_{\mathrm{v}} / \mathrm{F}_{\mathrm{m}}$ should not be treated as an indicator of damage, but rather as a symptom of adaptive or developmental changes. In turn, Souza et al. (2004) proved that the effect of drought stress induced a significant decrease of $F_{v} / F_{m}$ only in case of severe drought stress.

Another studied parameter of $\mathrm{Chl}$ fluorescence was the area above the induction curve of fluorescence between the values $F_{0}$ and $F_{m}$ (Area). It expresses the size of the reduced plastoquinone pool. Blocking electron transport from reaction centers to plastoquinone, which occurs during stress, leads to a decrease of the Area value. This may partly indicate negative physiological effects of the water deficit (lower hydratation leads to lower values of the parameter Area, and thus a lower amount of electron acceptors on the reduction side of PSII). In presented work, tested cultivars both of yellow lupin and pea plants were characterized by the decline of Area. Generally, in lupin, the reduction was observed immediately on the $1^{\text {st }}$ day of drought, while pea showed the decline on the $14^{\text {th }}$ day of drought. Then, in our experiments the applied mild drought stress turned out to be sufficient to obstruct electron transport from reaction centers of PSII.

The stress can also lead to a decrease of electron transport efficiency in PSII (ET $0 / \mathrm{CS})$. Therefore, reduced $\mathrm{ET}_{0} / \mathrm{CS}$ indicates that active reaction centers (RCs) are converted into inactive $\mathrm{RCs}$, reducing the efficiency of trapping and a decline in PSII activity (Fghire et al. 2015). In our studies, this parameter did not show significant changes when exposed to the applied soil stress treatment and its values ranged from 213 to 240 . Perhaps, the applied mild soil drought was too weak to inactivate a sufficiently large number of RCs which could significantly reduce the value of $\mathrm{ET}_{0} / \mathrm{CS}$. This result may indicate the insignificant usefulness of this parameter for the assessment of the functioning of legumes photosynthetic apparatus under mild drought conditions.

The last selected parameter was the performance index of PSII (PI). It provides useful quantitative information about the state of plants and their vitality (Kalaji et al. 2011) and therefore can be used for the analysis of plant stress response. In general, PI describes the energy conservation between photons absorbed by PSII and the reduction of intersystem electron acceptors (Fghire et al. 2015). The PI is positively correlated with the availability of water for plants - the higher water availability, the higher the value of PI. This integrative parameter includes three independent parameters: (1) density of fully active reaction centers (RCs), (2) efficiency of electron movement by trapped exciton into the electron transport chain beyond the $\mathrm{Q}_{\mathrm{A}}$, and (3) the probability that an absorbed photon will be trapped by RCs. The PI reflects the functionality of both PSI and PSII and gives us quantitative information on the current state of plant performance under stress conditions (Strasser et al. 2004). Moreover, some authors consider PI as a potential indicator of the effects of drought stress before appearance of visible physiological disturbances. Other authors claim that PI seems to be one of the most useful FC parameters (Czyczyło-Mysza et al. 2013). Therefore, PI has been widely used to screen for the response to water shortages in many plants species, such as barley, soybean, wheat, and sesame (Çiçek et al. 2015). The studies on chickpea (Cicer arietinum L.) cultivars revealed the reduction of PI values under drought 
(Çiçek et al. 2015). Also in quinoa plants (Chenopodium quinoa Willd.) under field conditions of varying water availability, large changes in the PI were demonstrated (Fghire et al. 2015). Likewise, in our studies, PI showed significant changes in response to soil drought conditions. In yellow lupin cv. 'Taper' and both pea cultivars, its value decreased significantly on the $1^{\text {st }}$ and $14^{\text {th }}$ day of drought. Only 'Morocco 4' was characterized by an increase of PI on the $14^{\text {th }}$ day. It seems that this more tolerant cultivar (probably due to its geographical origin) maintained a relatively high efficiency of the photosynthetic apparatus under the applied mild stress conditions. This is reflected also in the lack of significant changes of the other two tested parameters of Chl fluorescence as well as stable SPAD values even in spite of the decreased LRWC.

The obtained results showed diverse photosynthetic activity and adaptation of the photosynthetic apparatus of the tested plants to drought conditions. This variability is noticeable within and between species and makes it more difficult to uniquely identify the one universal Chl fluorescence parameter that can be used as an indicator of soil drought tolerance in leguminous plants. However, among discussed parameters, three of them, $F_{v} / F_{m}$, Area, and PI, seem to be appropriate to present changes in the functioning of the photosynthetic apparatus of legumes under soil drought conditions. These parameters were the most susceptible to the applied stress at its mild intensity showing significant changes. Souza et al. (2004) concluded that PSII is more resistant to water deficit, compared with PSI, and the effect of stress on the course of the photochemical reaction is manifested only in the prolonged and severe drought stress. Perhaps, also in our studies, choosing a longer and more intense drought (or applying it in a different phase of the plant growth) could provide various observations and conclusions.

The water shortage is an important environmental factor in plant productivity (Razmjoo et al. 2008). The results show that the increasing intensity of drought stress reduces the biological yield. According to Mafakheri et al. (2010), drought had a significant effect on the number of pods and on the plant height. Tested chickpea plants (Cicer arietinum L.) were usually tallest and had the highest number of pods when they were grown under control conditions. Karam et al. (2007) showed that in soybean (Glycine max Merr.), while increasing the intensity of stress, drought reduced the leaf area index and yield components. Also Osman (2015) showed the reduction of the number of pea pods per plant under drought conditions. Moreover, the results of Kulig and Ziółek (1997) indicate the number of pods and the 1,000-seed mass as the most important components of the legumes yield. In our experiment, the number of pods of pea was altered under soil drought conditions, and the number of seeds per plant as well as the 1,000-seed mass significantly decreased in both legume species. Droughtstressed plants produced fewer, smaller seeds and were characterized by shorter shoots.

Improvement of yield and maintaining yield stability of crops, under optimal as well as drought stress conditions, is essential for the food security of the growing global population (Basu et al. 2016). Therefore, it is advisable to conduct further research on the tolerance for environmental stresses, with particular emphasis on drought, especially in species with nutritional and economic value, just like legume species.

Conclusion: In summary, we showed that the studied cultivars differed in their response to drought. The measurement of chlorophyll $a$ fluorescence parameters, chlorophyll concentration in SPAD units, yield components, and their analysis can be used for screening of plant drought susceptibility. However, the ability to deal with drought can depend on many mechanisms, including the ability to maintain high LRWC as well as changes in biochemical profile which are the goal for the future studies.

\section{References}

Anjum S.A., Xie X., Wang L. et al.: Morphological, physiological and biochemical responses of plants to drought stress. - Afr. J. Agr. Res. 6: 2026-2032, 2011.

Antonkiewicz J., Rapacz M.: [Assessment of photosynthetic activity of plants grown on stubble sediments and furnace ash.] - Zesz. Probl. Post. Nauk Rol. 509: 187-196, 2006. [In Polish]

Ashraf M., Harris P.J.C.: Photosynthesis under stressful environments: An overview. - Photosynthetica 51: 163-190, 2013.

Ashraf M., Karim F.: Screening of some cultivars/lines of black gram (Vigna mungo (L.) Hepper) for resistance to water stress. - Trop. Agr. 68: 57-62, 1991.

Baker N.R.: Chlorophyll fluorescence: A probe of photosynthesis in vivo. - Annu. Rev. Plant Biol. 59: 89-113, 2008.

Barrs H.D., Weatherley P.E.: A re-examination of the relative turgidity technique for estimating water deficits in leaves. Aust. J. Biol. Sci. 15: 413-428, 1962.

Basu S., Ramegowda V., Kumar A., Pereira A.: Plant adaptation to drought stress. - F1000Res. 5: 1554, 2016.

Batra N.G., Sharma V., Kumari N.: Drought-induced changes in chlorophyll fluorescence, photosynthetic pigments, and thylakoid membrane proteins of Vigna radiata. - J. Plant Interact. 9: 712-721, 2014.

Bieniaszewski T., Podleśny J., Olszewski J. et al.: [The response of indeterminate and determinate yellow lupin varieties to different plant density.] - Frag. Agron. 29: 7-20, 2012. [In Polish]

Björkman O., Demmig B.: Photon yield of $\mathrm{O}_{2}$ evolution and chlorophyll fluorescence characteristics at $77 \mathrm{~K}$ among vascular plants of diverse origins. - Planta 170: 489-504, 1987.

Cassol D., De Silva F.S.P., Falqueto A.R., Bacarin M.A.: An evaluation of non-destructive methods to estimate total chlorophyll content. - Photosynthetica 46: 634-636, 2008.

Chaves M.M., Flexas J., Pinheiro C.: Photosynthesis under drought and salt stress: regulation mechanisms from whole plant to cell. - Ann. Bot.-London 103: 551-560, 2009.

Çiçek N., Arslan Ö., Çulha-Erdal Ş. et al.: Are the photosynthetic performance indexes and the drought factor index satisfactory selection criterion for stress? - Fresen. Environ. Bull. 24: 4190-4198, 2015.

Czyczyło-Mysza I., Tyrka M., Marcińska I. et al.: Quantitative trait loci for leaf chlorophyll fluorescence parameters, chlorophyll and carotenoid contents in relation to biomass and yield in bread wheat and their chromosome deletion bin. Mol. Breeding 32: 189-210, 2013. 
Dahl W.J., Foster L.M., Tyler R.T.: Review of the health benefits of peas (Pisum sativum L.). - Brit. J. Nutr. 108: 3-10, 2012.

Daryanto S., Wang L., Jacinthe P.A.: Global synthesis of drought effects on food legume production. - PLoS ONE 10: e0127401, 2015.

Estill K., Delaney R.H., Smith W.K., Ditterline R.L.: Water relations and productivity of alfalfa leaf chlorophyll variants. Crop Sci. 31: 1229-1233, 1991.

Fghire R., Anaya F., Ali O.I. et al.: Physiological and photosynthetic response of quinoa to drought stress. - Chil. J. Agr. Res. 75: 174-183, 2015.

Hsiao T.C.: Plant responses to water stress. - Ann. Rev. Plant Physio. 24: 519-570, 1973.

Jeuffroy M.H., Ney B.: Crop physiology and productivity. Field Crop. Res. 53: 3-16, 1997.

Juzoń K., Czyczyło-Mysza I., Marcińska I. et al.: Polyamines in yellow lupine (Lupinus luteus L.) tolerance to soil drought. Acta Physiol. Plant. 39: 202, 2017.

Juzoń K., Skrzypek E., Czyczyło-Mysza I. et al.: Effect of soil drought on the yield structure, protein and phenolics content in Pisum sativum and Lupinus luteus. - Acta Agron. Hung. 61: 267-278, 2013

Kalaji H.M., Bosa K., Kościelniak J. et al.: Chlorophyll a fluorescence - a useful tool for the early detection of temperature stress in spring barley (Hordeum vulgare L.). Omics 15: 925-934, 2011.

Kalaji H.M., Jajoo A., Oukarroum A. et al.: Chlorophyll a fluorescence as a tool to monitor physiological status of plants under abiotic stress conditions. - Acta Physiol. Plant. 38: 100-111, 2016.

Karam F., Masaad R., Sfeir T. et al.: Evapotranspiration and seed field of field grown soybean under deficit irrigation conditions. - Agr. Water Manage. 75: 226-244, 2007.

KautskyH.,HirschA.:NeueVersuchezurKohlensäureassimilation. - Naturwissenschaften 19: 964, 1931.

Kawakami K., Umena Y., Kamiya N., Shen J.R.: Location of chloride and its possible functions in oxygen-evolving photosystem II revealed by X-ray crystallography. - P. Natl. Acad. Sci. USA 106: 8567-8572, 2009.

Komura M., Yamagishi A., Shibata Y., et al:: Mechanism of strong quenching of photosystem II chlorophyll fluorescence under drought stress in a lichen, Physciella melanchla, studied by subpicosecond fluorescence spectroscopy. - BBA 1797: 331-338, 2010

Konica Minolta: Chlorophyll meter SPAD-502Plus, 2009. Available at: https://www.konicaminolta.com/instruments/ download/catalog/color/pdf/spad502plus catalog eng.pdf

Kościelniak J., Filek W., Biesega-Kościelniak J.: The effect of drought stress on chlorophyll fluorescence in Lolium-Festuca hybrids. - Acta Physiol. Plant. 28: 149-158, 2006.

Kulig B., Ziółek W.: [Yielding of morphologically diverse varieties of pea and faba bean depending on nitrogen fertilization.] - Zesz. Probl. Post. Nauk Rol. 446: 207-212, 1997. [In Polish]

Lawson T., Oxborough K., Morrison J.I.L., Baker N.R.: Responses of photosynthetic electron transport in stomatal guard and mesophyll cells in intact leaves to light, $\mathrm{CO}_{2}$, and humidity. - Plant Physiol. 128: 52-62, 2002.

Lazacano-Ferrat I., Lovat C.J.: Relationship between relative water content, nitrogen pools, and growth of Phaseolus vulgaris L. and P. acutifolius A. Gray during water deficit. Crop. Sci. 39: 467-475, 1999.

Lichtenthaler H.K., Buschmann C., Rinderle U., Schmuck G.: Application of chlorophyll fluorescence in ecophysiology. Radiat. Environ. Bioph. 25: 297-308, 1986.

Liu J.H., Nada K., Honda C. et al.: Polyamine biosynthesis of apple callus under salt stress: importance of arginine decarboxylase pathway in stress response. - J. Exp. Bot. 57: 2589-2599, 2006.

$\mathrm{Lu} \mathrm{C.,} \mathrm{Zhang} \mathrm{J.:} \mathrm{Effects} \mathrm{of} \mathrm{water} \mathrm{stress} \mathrm{on} \mathrm{photosystem} \mathrm{II}$ photochemistry and its thermostability in wheat plants. J. Exp. Bot. 50: 1199-1206, 1999.

Mafakheri A., Siosemardeh A., Bahramnejad B. et al.: Effect of drought stress on yield, proline and chlorophyll contents in three chickpea cultivars. - Aust. J. Crop Sci. 4: 580-585, 2010.

Marcińska I., Czyczyło-Mysza I., Skrzypek E. et al.: Application of photochemical parameters and several indices based on phenotypical traits to assess intraspecific variation of oat (Avena sativa L.) tolerance to drought. - Acta Physiol. Plant. 39: 153, 2017.

Maxwell K., Johnson G.N.: Chlorophyll fluorescence a practical guide. - J. Exp. Bot. 51: 659-668, 2000.

Medrano H., Escalona J.M., Bota J. et al.: Regulation of photosynthesis of $\mathrm{C}_{3}$ plants in response to progressive drought: the stomatal conductance as a reference parameter. - Ann. Bot.London 89: 895-905, 2002.

Murchie E.H., Lawson T.: Chlorophyll fluorescence analysis: a guide to good practice and understanding some new applications. - J. Exp. Bot. 64: 3983-3998, 2014.

Ohashi Y., Nakayama N., Saneoka H., Fujita K.: Effects of drought stress on photosynthetic gas exchange, chlorophyll fluorescence and stem diameter of soybean plants. - Biol. Plantarum 50: 138-141, 2006.

Osman H.S.: Enhancing antioxidant-yield relationship of pea plant under drought at different growth stages by exogenously applied glycine betaine and proline. - Ann. Agr. Sci. 60: 389-402, 2015.

Pinheiro C., Chaves M.M., Ricardo C.P.: Alterations in carbon and nitrogen metabolism induced by water deficit in the stems and leaves of Lupinus albus L. - J. Exp. Bot. 52: 1063-1070, 2001.

Podleśna A., Podleśny J., Doroszewski A.: Usefulness of selected weather indices to evaluation of yellow lupine yielding possibility - Agr. Water Manage. 146: 201-207, 2014.

Qiu N., Lu C.: Enhanced tolerance of photosynthesis against high temperature damage in salt-adapted halophyte Atriplex centralasiatica plants. - Plant Cell Environ. 26: 1137-1145, 2003.

Ramos M.L.G., Parsons R., Sprent J.I., James E.K.: Effect of water stress on nitrogen fixation and nodule structure of common bean. - Pesqui. Agropecu. Bras. 38: 339-347, 2003.

Razmjoo K., Heydarizadeh P., Sabzalian M.S.: Effect of salinity and drought stresses on growth parameters and essential oil content of Matricaria chamomila. - Int. J. Agric. Biol. 10; 451-454, 2008.

Reckling M., Bergkvist G., Watson C.A. et al.: Trade-offs between economic and environmental impacts of introducing legumes into cropping systems. - Front. Plant Sci. 7: 669, 2016.

Roháček K.: Chlorophyll fluorescence parameters: the definitions, photosynthetic meaning, and mutual relationships. Photosynthetica 40: 13-29, 2002.

Souza R.P., Machado E.C., Silva J.A.B. et al.: Photosynthetic gas exchange, chlorophyll fluorescence and some associated metabolic changes in cowpea (Vigna unguiculata) during water stress and recovery. - Environ. Exp. Bot. 51: 45-56, 2004.

Strasser R.J., Tsimilli-Michael M., Srivastava A.: Analysis of the chlorophyll $a$ fluorescence transient. - In: Papageorgiou G.C., Govindjee (ed.): Chlorophyll $a$ Fluorescence: A Signature of Photosynthesis. Advances in Photosynthesis and Respiration. Pp. 321-362. Springer, Dordrecht 2004. 
Tavoletti S., Iommarini L., Mogliani L. et al.: Agronomic, qualitative (b-ODAP) and molecular variability in grasspea populations of the Marche region (central Italy). - Food Chem. Toxicol. 49: 601-606, 2011.

Tsonev T., Wahbi S., Sun P. et al.: Gas exchange, water relations photochemical reflectance index in stress and recovery and their relationships with Quercus ilex plants during water stress and recovery. - Int. J. Agric. Biol. 16: 335-341, 2014.
Vyas S.P.: Impact and strategies for yield improvement of arid legumes under drought. - Int. J. App. Life Sci. Eng. 1: 12-19, 2014.

Zaghloul R.A., Abou-Aly H.E., El-Meihy R.M., El-Saadony M.T.: Improvement of growth and yield of pea plants using integrated fertilization management. - Univ. J Agr. Res. 3: 135-143, 2015.

(C) The authors. This is an open access article distributed under the terms of the Creative Commons BY-NC-ND Licence. 